\title{
Sarcoptes Scabiei Infestation in Iran: A Brief Review Report
}

Roghayeh Norouzi (PhD)

Department of Pathobiology, Faculty of Veterinary Medicine, University of Tabriz, Tabriz, Iran

Corresponding author: Roghayeh Norouzi

Tel: +989141067103

Email:

roghayehnorouzi123@gmail.com

Address: Faculty of Veterinary

Medicine, University of Tabriz, Tabriz, Iran

Received: 03 Mar 2019

Revised: 03 Jul 2019

Accepted: 03 Jul 2019

\section{cc) (i) (8)}

This work is licensed under a Creative Commons Attribution 4.0 License.

\section{ABSTRACT}

Background and objectives: Sarcoptes scabiei is a microscopic parasitic arthropod that penetrates into epidermis of the skin and causes scabies, a contagious disease that is one of the most common causes of dermatosis in the world.

Methods: We herein summarize published papers about Sarcoptes scabiei infestation in Iran. Databases including MEDLINE, Pubmed and Google scholar were searched using the following terms: Sarcoptes scabiei, mange, prevalence of Sarcoptes scabiei and scabies status in Iran.

Results: 0verall, we found approximately 15 articles related to the prevalence of Sarcoptes scabiei infestation in Iran. According to these studies, the prevalence of Sarcoptes scabiei infestation has been rather high in Iran during war and in prisons and humid areas of the country.

Conclusion: In spite of the low prevalence of scabies, it is necessary to implant prevention programs continuously by reducing overcrowding, improving health education, personal hygiene, diagnostics tools, and screening and treatment of high-risk populations.

Keywords: Sarcoptes scabiei, Brief review, Iran.

This paper should be cited as: Roghayeh Norouzi [Sarcoptes Scabiei Infestation in Iran: A Brief Report]. mljgoums. 2020; 14(2): 42-44 


\section{INTRODUCTION}

Sarcoptes scabiei var. hominis, the human itch mite, is an Acarina mite from the Astigmata order, family Sarcoptidae. Itch mites penetrate into the epidermis but never beyond the stratum corneum. Other races of scabies mites can cause infestation in other mammalian hosts (1).

The itching in scabies results from body's allergic reaction to the mites, their eggs and their waste. Allergic reaction to mites plays a main role in development of lesions and pruritus (2). The rise in the population, absence of hygiene facilities, war, floods, earthquakes and other natural disasters all contribute to the increased frequency of scabies (3). Transmission occurs via direct contact with an infected person and his/her clothes, bedclothes, etc.

Mite species infects parts of the body with delicate, wrinkled and damp skin such as the back, palms and spaces between the fingers, wrist, elbow, armpit, groin and nipples (1). A broad range of clinical appearances may be seen in scabies, nocturnal itching and cutaneous lesions, including classic pruritic papules and burrows to secondary features such as impetigo. Pruritus, the main clinical manifestation, is caused by hypersensitivity to debris, eggs and feces, rather than by direct effects of the mite. The primary lesions appear 3-10 days after exposure to the mite. These lesions include burrows, papules, vesicles and pustules. Nocturnal pruritus is a characteristic of scabies. Main presenting features include rash and intense itching. Bullous lesions are less frequent (2). In Iran, scabies is considered a major public health problem. According to previous studies in Iran, the rate of scabies infestation ranges between $1.3 \%$ and $57 \%$ (4). In this report, we summarise the latest published papers about Sarcoptes scabiei infestation in Iran.

\section{MATERIALS AND METHODS}

Articles were selected from the MEDLINE, PubMed, Scopus, Science Direct, Web of Science and Google Scholar databases. In addition, Persian databases including Magiran, Iran Medex, Iran Doc and SID were searched. The search was performed using the following terms: Sarcoptes scabiei, mange, prevalence of Sarcoptes scabiei, scabies diagnosis, scabies treatment and scabies status in Iran. A comprehensive search was conducted on all published and unpublished articles including full texts, abstracts and parasitology congress summaries.

\section{DISCUSSION}

Sarcoptes scabiei, var. hominis infestation is a highly contagious skin disease that is found all over the world. Scabies is a major public health threat in developing countries and the incidence of the disease is generally higher in rural areas with poor hygiene and low education level. The prevalence of scabies is higher in children under five years of age (77\%), peaking to $86 \%$ among those ages 5 to 9 years old, and declines steadily with age (3).

Sarcoptes scabiei infestation is more prevalent in northern parts of Iran such as the Golestan, Mazandaran and Gilan provinces but less common in the southern and central regions. Thus, it can be inferred that the contamination is more frequent in the humid areas of Iran. Due to the high prevalence of scabies in the northern parts of Iran, appropriate strategies are required to prevent and control the disease. The prevalence of scabies is higher in the Gilan (87\%) and Mazandaran (68\%) provinces. In a three-year study at the dermatology clinic of Razi Hospital in Rasht, a high prevalence of scabies was reported (9\%). Scabies outbreak in the Gilan Province appears to be higher than other provinces, which is probably due to the relatively higher population density and the humid climate (5).

In Port of Bushehr, a cross-sectional study on 3913 elementary school students (1951 girls and 1962 boys) reporte, the rate of scabies to be $2.1 \%$ (6). In a study by Daliri et al. on pupils of elementary schools in Bandar-e Anzali, the prevalence of scabies was $5.93 \%$ and $7.22 \%$ in the urban and rural schools, respectively (7). In a study on 3545 prisoners in the central prison of Kerman, the prevalence of scabies was $1.2 \%$ (8). Roodsari et al. reported a prevalence of $2.2 \%$ for scabies among 1404 prisoners in Ghezel Hesar prison (9).

In a study on patients referred to Health centers of Kashan (central Iran) during 20102014, 21.7\% of the patients were Sarcoptes positive. In addition, the frequency of Sarcoptes was higher in males $(23 \%)$ than in females (20.6\%) (10).

Necessary training should be provided to healthcare personnel for rapid examination, 
diagnosis, treatment and follow-up of suspected cases.

\section{CONCLUSION}

In spite of the low prevalence of scabies, it is necessary to implant prevention programs continuously by reducing overcrowding, improving health education, personal hygiene, diagnostics tools, and screening and treatment

\section{REFERENCES}

1. Alexander JO'D. Arthropods and human skin. Springer Science\& Business Media. 2012.

2. Lydden P. Navigating parasite webs and parasite flow: Emerging and re-emerging parasitic zoonoses of wildlife origin. Int J Parasit. 2005; 35:11-12.

3. Poudat A, Nasirian H. Prevalence of pediculosis and scabies in the prisoners of Bandar Abbas, Hormozga province, Iran. Pakistan J Bio Sci. 2007; 10: 3967-3969.

4. Golchai J, Zargari O, Peinondi Gholipour M. The prevalence of scabies in the students of primary schools in somea-sara in 2000-2001: An observational crosssectional study. Iranian J of Dermatol. 2003; 25(7):2932.

5. Jehani M, Shirzad H, Mehrabitevana A. Investigation of prevalence rate of scabies in patient that suspected to scabies in military force in all united of Iran. J Military Med. 2001; 3: 195-9.

6. Arjomandzadeh S, Tahmasebi R, Jokar MH, Khatmi SM, Zarenejad M, Abdolazadeh-Lavari H. Prevalence of pediculosis and scabies in primary schools of Bushehr; 1999-2000. South Iramed JL. 2001; 1(4): 46-41. of high-risk populations.

\section{ACKNOWLEDGEMENTS}

We appreciate the cooperation of the Department of Parasitology, Faculty of veterinary medicine, University of Tabriz, Iran.

\section{CONFLICT OF INTEREST}

There are no conflicts of interest.

7. Daliri S, Shafiei A. Scabies and impetigo in primary school students in Anzali port. World Health J. 1994; 8: 57-9.

8. Shams AS, Nasiri KM, Sharifi I, Khajeh KAM, Pourlashkari M. Prevalence of infectious skin diseases in the central prison of Kerman. Iran J Dermatol. 2000; 4 (13): 19-25.

9. Roodsari MR, Malekzad F, Roodsari SR. Prevalence of scabies and pediculosis in Ghezel Hesar prison. Arch Clin Infect Dis. 2007; 2(2): 87-9.

10. Rasti S, Nazeri M, Kaveh E, Talaee R, Mousavi GA. Frequency and Clinical Manifestations of Scabies in Suspected Patients Referred to Health Centers of Kashan, Central Iran (2010 - 2014).Zahedan J Res Med Sci. 2017; 19(2): e7034. 